\title{
Experiencing more mathematics anxiety than expected? Contrasting trait and state anxiety in high achieving students
}

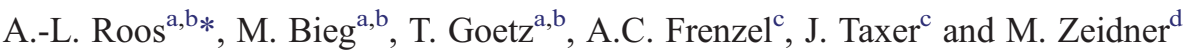 \\ ${ }^{a}$ Department of Empirical and Educational Research, University of Konstanz, Konstanz, \\ Germany; ${ }^{b}$ Thurgau University of Teacher Education, Kreuzlingen, Switzerland; ${ }^{c}$ Department \\ of Psychology, University of Munich, Munich, Germany; ${ }^{d}$ Department of Counseling and \\ Human Development, University of Haifa, Haifa, Israel
}

\begin{abstract}
This study examined mathematics anxiety among high and low achieving students $(N=237$, grades 9 and 10) by contrasting trait (habitual) and state (momentary) assessments of anxiety. Previous studies have found that trait anxiety measures are typically rated higher than state measures. Furthermore, the academic self concept has been identified to play a moderating role in the trait state discrepancy, with higher academic self concept leading to a lower dis crepancy (i.e. less overestimation of trait anxiety if state assessments reflect actual experience). Therefore, we assumed that high achievers who were expected to have high academic self concepts would exhibit a smaller trait state discrepancy than low achievers. Results confirmed these assumptions and revealed that high achievers even underestimated their trait anxiety. Implications are discussed.
\end{abstract}

Keywords: state; trait; intensity bias; anxiety; academic self concept; high achievers

\section{Introduction}

In comparison with low achievers, high achievers generally face fewer problems at school. One widespread problem in the school context is anxiety, which is a detrimental emotion in the classroom particularly in the domain of mathematics (Goetz \& Hall, 2013). A meta-analysis by Ma (1999) on math anxiety and its scholastic outcomes found that high achievers tend to be less anxious about mathematics than their low achieving peers. However, when comparing different levels of anxiety, it is important to distinguish between different assessment methods.

Students' class-related anxiety can be assessed using either trait or state assessment methods. Trait measures examine habitual anxiety, whereas state measures examine momentarily experienced anxiety in real-life situations (Spielberger, Gorsuch, \& Lushene, 1970). Existing studies on mathematics anxiety have predominately used the less costly and more convenient trait assessment method (Wilhelm, Perrez, \& Pawlik, 2011). However, in comparison with scores obtained by multiple state assessments, which are regarded as reflecting actual emotions as they are experienced (Robinson \& Clore, 2002), trait assessments of emotions are generally overestimated (Buehler \& McFarland, 2001). It has been argued that the discrepancy between trait and state measures of emotions (i.e. overestimation of trait emotions)

*Corresponding author. Email: anna lena.roos@uni konstanz.de 
results from trait measures being recall based, which causes them to be strongly influenced by subjective beliefs (Robinson \& Clore, 2002). Thus, trait measures are often believed to not reflect actual emotions (Robinson \& Clore, 2002). This raises the question of whether trait measures of anxiety are able to validly gauge what students actually feel in the classroom and calls for applying a state as well as a trait approach to assess students' emotions.

Therefore, the aim of this study was to compare the discrepancy between trait and state assessments of mathematics anxiety among the particular groups of high and low achievers. Thus, we assessed students' momentary mathematics anxiety during real-life mathematics class with a state-based measure and compared these ratings with the students' trait mathematics anxiety ratings. This rendered it possible to evaluate whether findings from previous studies assessing high achieving students' trait anxiety hold true when actual state anxiety measures are also assessed.

\section{The trait-state discrepancy in anxiety and the role of academic self-concept}

The discrepancy between trait and state self-reports of emotion (referred to from here on as the trait-state discrepancy) reflects the observation that trait emotions are usually overestimated in comparison with state emotions (also termed sometimes as intensity bias; Buehler \& McFarland, 2001). In their accessibility model of emotional self-report, Robinson and Clore (2002) postulated that subjective beliefs play an important role in the trait-state discrepancy. Their model proposes that trait measures, which examine habitual emotions, are strongly influenced by subjective beliefs because they are recall based. Whereas subjective beliefs are less impactful for state measures of emotions because they assess emotions as they are experienced. Therefore, state measures of momentary emotions are considered to evaluate actual emotions, while trait measures reflect individual's beliefs about emotions (Robinson \& Clore, 2002).

Concerning the trait-state discrepancy in anxiety, previous studies have found that academic self-concept, which is an identity-related subjective belief, influences the extent trait anxiety measures are overestimated in comparison with state anxiety measures (Bieg, Goetz, \& Lipnevich, 2014; Goetz, Bieg, Lüdtke, Pekrun, \& Hall, 2013). The academic self-concept is a mental representation of the abilities and competencies a person has (Nagengast \& Marsh, 2012) and can be defined as an evaluative self-perception that is formed through experience with and interpretation of one's school environment (Marsh \& Craven, 1997). Specifically, studies have found that the trait-state discrepancy for anxiety (i.e. the overestimation of trait anxiety) is smaller for students with higher academic self-concepts (Bieg et al., 2014; Goetz et al., 2013). This smaller trait-state discrepancy in students with higher academic self-concepts implies that these students show a lower overestimation of trait in comparison with state anxiety levels. Since state measures are assumed to assess actual emotions, a smaller trait-state discrepancy in emotional self-reports can be viewed as a more realistic evaluation of trait anxiety because it is less overestimated. Thus, students with a high academic self-concept should evaluate their anxiety more realistically than students with a low academic self-concept. Research comparing the academic self-concepts of high and low achieving students has shown that high achieving students report higher levels of academic self-concept (Bailey, 1971). Therefore, we assumed that high achievers, who are also expected to have high academic self-concepts, would have a smaller trait-state discrepancy in mathematics 
anxiety (i.e. less overestimation of trait anxiety), meaning that they would evaluate their anxiety more realistically.

\section{The present research}

The aim of this study was to examine the trait-state discrepancy in mathematics anxiety among high and low achievers, and to further investigate academic self-concept as a predictor of the trait-state discrepancy. Prior studies have shown that academic achievement (Ma, 1999) is negatively related to trait mathematics anxiety. Furthermore, high achievers can be assumed to have higher subjective control appraisals in classroom situations than low achievers, which as assumed by the control-value theory (Pekrun, 2006) should result in high achievers also experiencing less state anxiety than low achievers. Therefore, we assumed that high achievers would experience less trait as well as state mathematics anxiety than low achievers (Hypothesis 1). Furthermore, since previous studies have found a discrepancy between ratings of trait and state mathematics anxiety, which was smaller in students with a higher academic self-concept in mathematics (Bieg et al., 2014; Goetz et al., 2013), we expected high achievers to have a smaller trait-state discrepancy in mathematics anxiety than low achievers. This smaller discrepancy was expected to be due to a large extent to high achievers having a higher mathematics self-concept than low achievers. In more technical terms, we expected achievement group (high vs. low achievers) to moderate the trait-state discrepancy in mathematics anxiety (Hypothesis 2). Furthermore, we expected mathematics self-concept to partially mediate the relationship between the achievement groups (high vs. low achievers) and the trait-state discrepancy (Hypothesis 3; i.e. mediated moderation; Preacher, Rucker, \& Hayes, 2007). Figure 1 is a graphical depiction of our expectations for the high achieving students.

\section{Methods}

\section{Sample}

This study was part of a large research project that examined students' emotions in mathematics using both trait and state assessment methods. For the current study, a subsample of $N=237 \mathrm{high}$ and low achieving students (from 43 classes at 21 schools; $47 \%$ female, $M_{\text {age }}=15.71$ years, $\mathrm{SD}=.78$ ) was retained from an initial sample consisting of $N=828$ students (50.6\% female). The students were in the 9th $(57.4 \%)$ and 10th (42.6\%) grades and attended the top track of the German education system (i.e. Gymnasium; approximately one-third of the total student cohort in Germany attend this track; Federal Statistical Office [Statistisches Bundesamt], [Statistisches Bundesamt], [Statistisches Bundesamt], 2015).

For this study, the high and low achievement groups were defined using students' self-reported midterm mathematics grades. Grades in the German school system range from 1, very good, to 6, insufficient, with higher numbers representing poorer performance. Midterm grades additionally differentiate within grades by applying 0.25 gradations (e.g. grade 1 is subdivided into grades $1,1.25,1.5$, and 1.75). In this study, high achievers were defined as students whose mathematics grades were better than good (i.e. <2). Low achievers were defined as students whose mathematics grades were sufficient or worse (grades 4 to 6). Based on this definition, $N=116$ students ( $14 \%$ of the entire sample, $55 \%$ female) were labeled as 


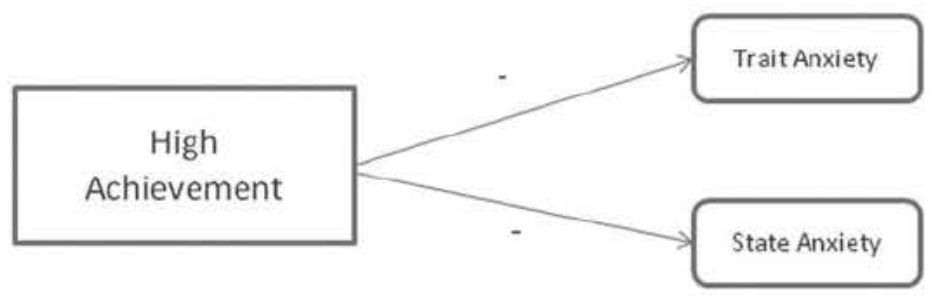

$\mathrm{H} 2$

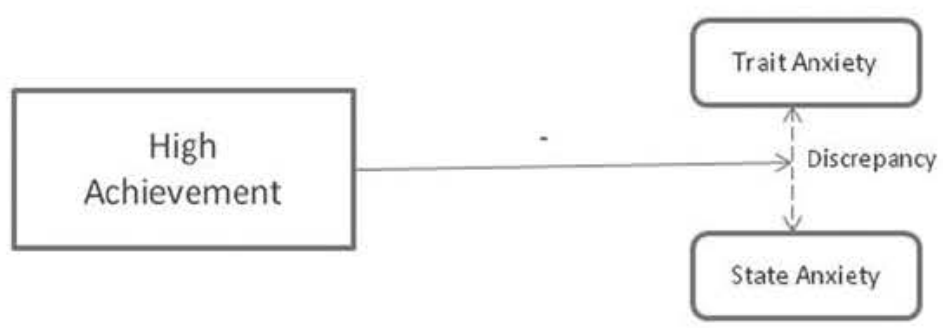

H3

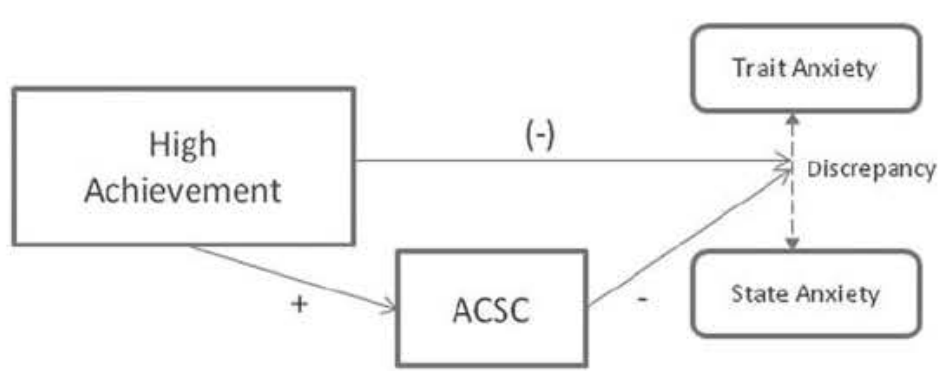

Figure 1. Graphical depiction of the expected results for the high achieving students (hypotheses 13 ).

Note: $\mathrm{H}=$ hypothesis, $\mathrm{ACSC}=$ academic self concept.

high achievers and $N=121$ students ( $14.6 \%$ of the entire sample, $49 \%$ female) were labeled as low achievers. Since we were only interested in the two extreme groups of high and low achievers, students with a good or satisfactory academic performance (grades 2-3.75) were excluded from the present analyses.

\section{Procedure}

After students consented to participate in the study, trait mathematics anxiety, mathematics self-concept and demographic data were assessed using a paper-and-pencil questionnaire that was administered by trained researchers. The state assessment phase began directly after the trait assessment of anxiety and lasted for 3 weeks. State mathematics anxiety was assessed via a personal diary that was designed as a short questionnaire to be filled out by each student after each mathematics lesson. Students who made fewer than three diary entries were excluded from the analyses. In total, this resulted in $N=1687$ state assessments (diary entries) with an average of $7.12(\mathrm{SD}=2.40$; range: $3-14)$ state assessments per student. 


\section{Study measures}

Trait and state mathematics anxiety

Since we wanted to compare levels of mathematics anxiety as assessed by trait vs. state measures, we used parallel item wording and an identical answer format for both assessment types. Trait and state mathematics anxiety were each assessed with two items. Trait anxiety items were developed for a study that analyzed learning and achievement in mathematics (PALMA; Goetz, 2004; Pekrun, Goetz, \& Frenzel, 2006). The trait anxiety items included the following: "When thinking of mathematics classes I am worried" and "I usually experience anxiety in mathematics classes". The sample specific internal consistency of this 2 -item scale was $\alpha=.63$. The parallel item wordings for the state anxiety items were as follows: "In this mathematics class I was worried" and "In this mathematics class I experienced anxiety" (the reliability of this 2 -item scale was $\alpha=.75$ ). Responses were made on a 5-point Likert-type scale ranging from 1, strongly disagree, to 5, strongly agree.

\section{Assessment of mathematics self-concept}

The academic self-concept in the domain of mathematics was assessed via three items (the reliability of this 3-item scale was $\alpha=.94$ ) adapted from Marsh's SelfDescription Questionnaire (SDQ; Marsh, 1990; German version, Kunter et al., 2002; sample item: "I have always done well in mathematics"). Responses were made on a 5-point Likert-type scale ranging from 1, strongly disagree, to 5, strongly agree.

\section{Data analysis}

Comparison of mean levels

As a first step, we conducted $t$-tests to compare high and low achievers trait anxiety, state anxiety and academic self-concepts. Effect sizes are reported as Cohen's $d$ (Cohen, 1988).

\section{Hierarchical linear regression}

Similar to previous research (e.g. Bieg et al., 2014; Goetz et al., 2013), we used a multilevel, intraindividual modeling approach to evaluate our hypotheses. This analyses method was chosen to account for the nested structure of the data (multiple measurement points per student and students from different classes) and because there were different numbers of state assessment measurement points per student. Our three-level multilevel analyses (measurement points nested within students and students nested within classrooms) were conducted using Hierarchical Linear Modeling software (Version 7.01; Raudenbush, Bryk, Cheong, Congdon, \& du Toit, 2011).

\section{Level 1 (measures within students)}

Since we were interested in the discrepancy between students' trait and state mathematics anxiety ratings (i.e. trait-state discrepancy), students' anxiety scores served as the outcome variable in all the hierarchical linear regression models. We formed this outcome variable by including the one trait anxiety score and several state anxiety scores of each student into one variable. Thereby, the outcome variable comprised 
of two types of measures (one trait and several state measures) for each person. Including the combined variable in the analyses is only meaningful when a dichotomous independent variable, in the present analyses labeled as "State/Trait" (uncentered), is simultaneously introduced on Level 1 . In this dichotomous variable, the state measures were coded as 0 and the trait measures were coded as 1 . This coding scheme allowed the state and trait measures of anxiety to be separated in the analyses and the trait-state discrepancy in anxiety to be examined. Due to the coding of this variable, the intercept value $\left(\gamma_{000}\right)$ in all of our models represents the overall state anxiety mean when other linear terms are also coded as 0 . The effect of the State/Trait variable $\left(\gamma_{100}\right)$ can be interpreted as the difference between trait and state anxiety scores with positive values indicating that trait scores were higher than state scores (trait-state discrepancy).

\section{Level 2 (student level)}

Two Level 2 variables were included in the respective models, each as a predictor of the intercept and slope of the State/Trait variable. These Level 2 variables were "High/Low Achievers" ( $0=$ high, $1=$ low, uncentered $)$ and "Mathematics Self-concept" ( $z$ score standardized across students).

\section{Cross-level interactions level 1-level 2}

To analyze the effect of achievement group (High/Low Achievers) on the discrepancy between trait and state anxiety scores, a cross-level multiplicative interaction term was included in the respective models to predict the slope, namely State/ Trait $\times$ High/Low Achievers $\left(\gamma_{110}\right)$. To analyze the effect of academic self-concept in mathematics on the trait-state discrepancy, an additional interaction term was included, namely State/Trait $\times$ Mathematics Self-Concept $\left(\gamma_{120}\right)$.

\section{Level 3 (class level)}

The different classes $(N=43)$ in which students were nested constituted the third level. This level took the clustering of students within classes when estimating standard errors into account.

\section{Calculated models}

In order to test the study hypotheses as illustrated in Figure 1, the models described below were calculated, each of which was constructed as a slopes-as-outcome model (Raudenbush \& Bryk, 2002).

The mixed model regression equations for the three models were as follows:

\section{Model 1}

$Y_{i j k}$ [Anxiety measures $i$ of student $j$ in class $k$ ] $=\gamma_{000}+\gamma_{100}$ (State/Trait) $+\gamma_{010}$ $($ High/Low Achievers $)+\gamma_{110}($ State/Trait $\times$ High/Low Achievers $)+r_{0 j k}+r_{1 j k}($ State/ Trait) $+\mathrm{u}_{00 k}+\mathrm{e}_{i j k}$.

In Model 1, we investigated whether high achievers have lower state anxiety than low achievers (Hypothesis 1) by examining the effect of achievement group 
(High/Low Achievers; $\left.\gamma_{010}\right)$ on state anxiety. In this model, a significant positive effect of achievement group indicates that low achievers have significantly higher state anxiety ratings than high achievers. This model also investigated whether high achievers showed a smaller trait-state discrepancy than low achievers (Hypothesis 2) by examining the effect of the State/Trait $\times$ High/Low Achievers interaction $\left(\gamma_{110}\right)$. A significant positive effect of this interaction indicates that low achievers have a significantly larger trait-state discrepancy than high achievers.

\section{Model 2}

$Y_{i j k}$ [Anxiety measures $i$ of student $j$ in class $k$ ] $=\gamma_{000}+\gamma_{100}$ (State/Trait) $+\gamma_{020}$ (Mathematics Self-concept $)+\gamma_{120}($ State/Trait $\times$ Mathematics Self-concept $)+\mathrm{r}_{0 j k}+$ $\mathrm{r}_{1 j k}($ State/Trait $)+\mathrm{u}_{00 k}+\mathrm{e}_{i j k}$.

In Model 2, we investigated whether mathematics self-concept could predict the discrepancy between trait and state anxiety scores by examining the effect of the State/Trait $\times$ Mathematics Self-concept interaction $\left(\gamma_{120}\right)$. A significant negative effect of this interaction indicates that higher levels of mathematics self-concept correspond with a smaller trait-state discrepancy in mathematics anxiety.

\section{Model 3}

$Y_{i j k}$ [Anxiety measures $i$ of student $j$ in class $\left.k\right]=\gamma_{000}+\gamma_{100}$ (State/Trait) $+\gamma_{010}$ $($ High/Low Achievers $)+\gamma_{020}$ (Mathematics Self-concept) $+\gamma_{110}$ (State/Trait $\times$ High/ Low Achievers $)+\gamma_{120}$ (State/Trait $\times$ Mathematics Self-concept $)+\mathrm{r}_{0 j k}+\mathrm{r}_{1 j k}($ State/ Trait) $+\mathrm{u}_{00 k}+\mathrm{e}_{i j k}$.

Model 3 examined mathematics self-concept as a possible mediator of the trait-state discrepancy in mathematics anxiety among high vs. low achievers (Hypothesis 3). In this model, achievement group (High/Low Achievers) and mathematics self-concept were both included as predictors of the trait-state discrepancy $\left(\gamma_{110}, \gamma_{120}\right)$. With this model, we were able to see whether the effect of achievement group (High/Low Achievers) on the trait-state discrepancy $\left(\gamma_{110}\right)$, as tested by Model 1 , was reduced when mathematics self-concept was included in the model (mediated moderation).

To fully meet the criteria of mediated moderation as postulated by Preacher et al. (2007), we additionally tested whether achievement level predicted mathematics self-concept (mediator). Since these variables are both within person variables, we examined the Spearman correlation between mathematics self-concept and achievement because achievement was measured on an ordinal scale.

\section{Results}

\section{Comparison of mean levels}

Table 1 provides an overview of the mean level comparisons. T-tests revealed that, as anticipated, high and low achievers significantly differed in their trait and state anxiety levels and mathematics self-concepts. Specifically, high achievers reported less trait and state anxiety and higher mathematics self-concepts than low achievers. The effect sizes were medium to large. These results partly confirmed Hypothesis 1, in which we assumed that high achievers would report lower levels of trait anxiety than low achievers. Since trait anxiety was assessed with a single measurement point 
per student, we were able to use a $t$-test to examine the prediction made in Hypothesis 1 regarding trait anxiety. However, the prediction that high achievers would experience less state anxiety than low achievers (the second part of Hypothesis 1) could not be tested with a $t$-test due to the differing number of state anxiety assessments per student. So, we used Model 1 to further test the predictions made in Hypothesis 1.

\section{Hierarchical linear regression}

The results of the hierarchical linear regressions, including the regression coefficients and the variance components, as well as the explanatory power, are depicted in Table 2.

\section{Model 1}

In Model 1, the coefficient for the intercept $\left(\gamma_{000}\right)$ is interpreted as the mean state anxiety score for high achievers $\left(\gamma_{000}=1.53\right)$. Results showed that the effect of achievement group (High/Low Achievers; $\gamma_{010}$ ) on anxiety scores was significant $\left(\gamma_{010}=.36, p<.001\right)$. This effect corresponds to the $t$-tests results and can be interpreted as state anxiety scores being significantly lower in high achievers than in low achievers, which supports our first hypothesis. Analyses further revealed that the coefficient for the State/Trait variable $\left(\gamma_{100}\right)$ was significant $\left(\gamma_{100}=-.17, p<.05\right)$ and revealed that trait anxiety was lower than state anxiety in high achievers. This means that high achievers even underestimated their anxiety when judging it from a trait rather than a state perspective. Since this result was unexpected, we examined it further with post hoc analyses, which are described in the last paragraph of the results section.

The effect of the State/Trait $\times$ High/Low Achievers interaction $\left(\gamma_{110}\right)$ was significant $\left(\gamma_{110}=.64, p<.001\right)$ and revealed that the discrepancy between trait and state mathematics anxiety was higher for low achievers, as was proposed in Hypothesis 2. Hence, achievement level moderated the trait-state discrepancy in anxiety.

\section{Model 2}

In this model, the intercept coefficient $\left(\gamma_{000}\right)$ is interpreted as the mean state anxiety score for a student with a mean mathematics self-concept score (mathematics

Table 1. Descriptive statistics, mean level differences, and related effect sizes of key study variables.

\begin{tabular}{|c|c|c|c|c|c|c|}
\hline \multirow[b]{2}{*}{ Measure } & \multicolumn{2}{|c|}{$\begin{array}{c}\text { High } \\
\text { achievers } \\
(N=116)\end{array}$} & \multicolumn{2}{|c|}{$\begin{array}{c}\text { Low } \\
\text { achievers } \\
(N=121)\end{array}$} & \multirow[b]{2}{*}{$T(\mathrm{df})$} & \multirow[b]{2}{*}{ Cohen's $d$} \\
\hline & $M$ & SD & $M$ & SD & & \\
\hline Trait anxiety & 1.36 & .61 & 2.38 & 1.07 & $t(191.96)=9.12^{* * *}$ & .79 \\
\hline State anxiety & 1.53 & .55 & 1.92 & .58 & $t(235)=5.31^{* * *}$ & .37 \\
\hline Mathematics self concept & 4.51 & .68 & 1.79 & .67 & $t(235)=30.97 * * *$ & 2.34 \\
\hline
\end{tabular}

Notes: Positive $t$ values reflect higher scores for high achievers than for low achievers. For multi item measures, item means were used to calculate scale values.

$* * * p<.001$. 
Table 2. Results of models predicting mathematics anxiety.

\begin{tabular}{|c|c|c|c|}
\hline Level and predictor & Model 1 & Model 2 & Model 3 \\
\hline \multicolumn{4}{|l|}{ Level 1} \\
\hline Intercept $\left(\gamma_{000}\right)$ & $\begin{array}{l}1.53^{* * *} \\
(.05)\end{array}$ & $\begin{array}{l}1.70 * * * \\
(.04)\end{array}$ & $\begin{array}{l}1.85 * * * \\
(.10)\end{array}$ \\
\hline State/Trait anxiety $\left(\gamma_{100}\right)$ & $\begin{array}{l}.17^{*} \\
(.07)\end{array}$ & $\begin{array}{l}.13^{*} \\
(.06)\end{array}$ & $\begin{array}{c}.08 \\
(.11)\end{array}$ \\
\hline \multicolumn{4}{|l|}{ Level 2} \\
\hline High/Low achievers $\left(\gamma_{010}\right)$ & $\begin{array}{l}.36^{* * *} \\
(.09)\end{array}$ & & $\begin{array}{c}.31 \\
(.19)\end{array}$ \\
\hline Mathematics self concept $\left(\gamma_{020}\right)$ & & $\begin{array}{l}.23 * * * \\
(.04)\end{array}$ & $\begin{array}{l}.36^{* * *} \\
(.09)\end{array}$ \\
\hline \multicolumn{4}{|l|}{ Cross level interactions L1 L2 } \\
\hline State/Trait anxiety $\times$ High/Low achievers $\left(\gamma_{110}\right)$ & $\begin{array}{l}.64 * * * \\
(.09)\end{array}$ & & $\begin{array}{l}.10 \\
(.15)\end{array}$ \\
\hline State/Trait anxiety $\times$ Mathematics self concept $\left(\gamma_{120}\right)$ & & $\begin{array}{l}.34 * * * \\
(.05)\end{array}$ & $\begin{array}{l}.30 * * * \\
(.09)\end{array}$ \\
\hline \multicolumn{4}{|l|}{ Variance components } \\
\hline Within student $(\mathrm{L} 1)$ variance $\left(\sigma^{2}\right)$ & .437 & .437 & .437 \\
\hline Intercept (L2) variance $\left(\tau_{00}\right)$ & .233 & .210 & .203 \\
\hline Slope (L2) variance $\left(\tau_{11}\right)$ & .182 & .165 & .165 \\
\hline Intercept slope (L2) covariance $\left(\tau_{01}\right)$ & .063 & .089 & .088 \\
\hline Intercept (L3) variance & .019 & .023 & .027 \\
\hline Explanatory power & .617 & .653 & .653 \\
\hline
\end{tabular}

Notes: Description of variables: State/Trait $(0=$ state, $1=$ trait $)$; High/Low achievers $(0=$ high achievers, $1=$ low achievers); Mathematics self concept: $z$ standardized scale; $\mathrm{L}=$ Level; $N_{L I}=1924$ (measures within students), $N_{L 2}=237$ (measures between students), $N_{L 3}=43$ (measures between classes). Explanatory power refers to the proportion of slope variance explained by the L2 predictors. The slope variance of the model in which no cross level interactions are included was $\tau_{11}=.475$. Standard errors are in parentheses.

$* p<.05 ; * * * p<.001$. (In the above analyses, gender was not analyzed as a possible moderator because gender differences in anxiety were not the main concern of this study. However, as gender has been found to play a role in trait mathematic anxiety, but not in state mathematic anxiety (Goetz et al., 2013), we also calculated all models with gender as an additional variable. Results in these models revealed no significant effects of gender above and beyond the effects of self concept, and therefore, left the conclu sions of the study unaffected).

self-concept was $z$-standardized). The effect of the State/Trait $\times$ Mathematics Selfconcept $\left(\gamma_{120}\right)$ interaction was significant $\left(\gamma_{120}=-.34, p<.001\right)$. This effect showed that higher levels of mathematics self-concept correspond with smaller trait-state discrepancies in mathematics anxiety.

\section{Model 3}

In Model 3, the effect of the State/Trait $\times$ Mathematics Self-concept $\left(\gamma_{120}\right)$ interaction was significant $\left(\gamma_{120}=-.30, p<.001\right)$ and the effect of achievement group (High/Low Achievers) on the trait-state discrepancy $\left(\gamma_{110}\right)$ was no longer significant. In this model, the moderating effect of achievement group (High/Low Achievers) on the trait-state discrepancy $\left(\gamma_{110}\right)$ found in Model 1 was reduced and no longer significant when the State/Trait $\times$ Mathematics Self-concept interaction term $\left(\gamma_{120}\right)$ was included. 
The results of the Spearman correlation analyses showed that achievement and academic self-concept were significantly correlated, with higher achievement accompanied by higher levels of self-concept $(r=-.82, p<.01$; negative correlation due to higher grades indicating lower achievement in the German grading system). ${ }^{1}$ Therefore, academic self-concept met the criteria to be a mediator between achievement group and the trait-state discrepancy.

Along with the reduced effect of the State/Trait $\times$ High/Low Achievers $\left(\gamma_{110}\right)$ coefficient when the State/Trait $\times$ Mathematics Self-concept $\left(\gamma_{120}\right)$ interaction was added in Model 3, this shows that the moderating effect of achievement group (High/Low Achievers) on the trait-state discrepancy in mathematics anxiety (as found in Model 1) was mediated by academic self-concept. Thus, the described pattern is a mediated moderation (Preacher et al., 2007). Our results therefore support the assumption that achievement group moderates the trait-state discrepancy in mathematics anxiety (Hypothesis 2) and that the academic self-concept in the domain of mathematics mediates the relationship between achievement group and the trait-state discrepancy in mathematics anxiety (Hypothesis 3).

\section{Post hoc analyses}

Model 1 revealed that high achievers unlike low achievers did not overestimate their anxiety, but rather underestimated their trait anxiety. Since these results were surprising and unanticipated, we examined the distribution of the values for the trait-state discrepancy in high and low achievers (see Figure 2). To calculate these values, we subtracted students' mean trait anxiety scores from their mean state anxiety scores. Therefore, positive trait-state discrepancy values reflected an overestimation of trait anxiety, whereas negative values reflected an underestimation of trait anxiety. As depicted in Figure 2, the majority of high achievers underestimated their anxiety in the trait approach, whereas the majority of low achievers overestimated their trait anxiety.

\section{Discussion}

The aim of this study was to examine the trait-state discrepancy in mathematics anxiety among high and low achieving students while also taking into account their academic self-concepts in mathematics - an identity-related subjective belief previously shown to play a role in explaining the trait-state discrepancy in students' emotions (Goetz et al., 2013). We examined whether high achievers show a smaller trait-state discrepancy in mathematics anxiety in comparison with low achievers because as expected they have higher academic self-concepts in the domain of mathematics. If state anxiety reflects actual anxiety (Robinson \& Clore, 2002), this would imply that high achievers estimate their anxiety more realistically in comparison to low achievers.

Consistent with previous research (Ma, 1999) and supporting our first hypothesis, we found that high achievers reported lower levels of trait anxiety than low achievers. Extending previous research on trait anxiety, we also found that high achievers reported lower levels of state mathematics anxiety than low achievers. Furthermore, we found a discrepancy between trait and state self-reports of anxiety. The majority of low achievers rated their trait anxiety significantly higher than their state anxiety, which means that they overestimated their trait anxiety (e.g. Bieg et al., 2014). This 


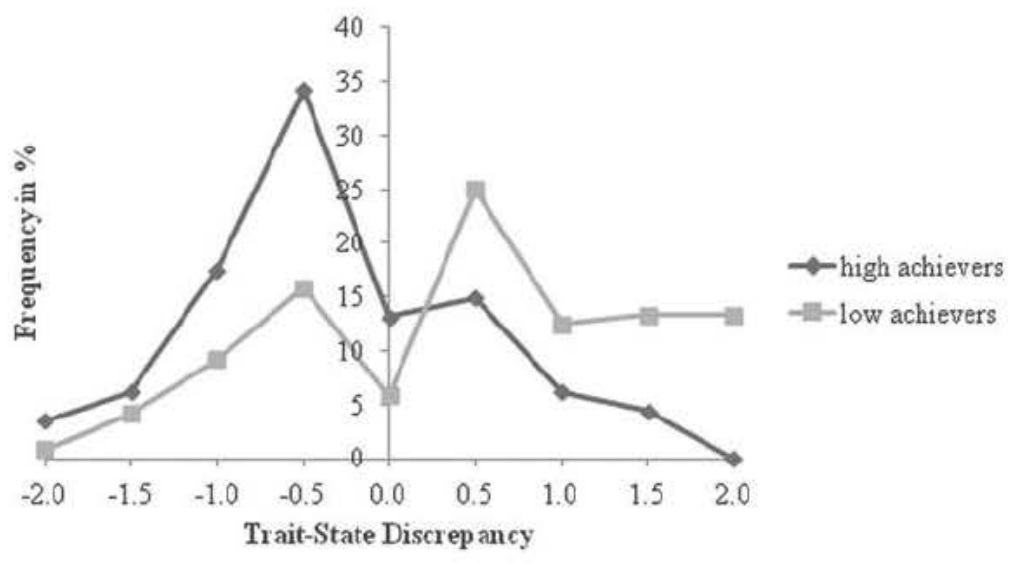

Figure 2. Distribution of high and low achievers' trait state discrepancy in mathematics anxiety.

Notes: The figure shows the distribution of the trait state discrepancy in mathematics anxiety for high and low achievers. The $x$ axis depicts the difference between trait and state anxiety measures with higher numbers indicating a stronger trait state discrepancy. To calculate these values, we subtracted students' mean trait anxiety scores from their aggregated state anxiety scores. For simplification, we applied .5 gradations to group the trait state discrepancy values. Negative values on the trait state discrepancy (i.e. trait anxiety was rated lower than state anxiety) are depicted on the left side of the $x$ axis (negative numbers), whereas positive val ues on the trait state discrepancy (i.e. trait anxiety was rated higher than state anxiety) are depicted on the right side of the $x$ axis. The $y$ axis depicts the frequencies (i.e. the percentage (\%) of students) in the respective groups (high vs. low achievers) for the different trait state discrepancies.

finding supports the intensity bias in emotional self-reports (Buehler \& McFarland, 2001). However, contrary to previous findings and our initial expectations, we did not find an overestimation of trait anxiety among high achievers. Even though the trait-state discrepancy in mathematics anxiety was lower in high achievers than in low achievers, as assumed in our second hypothesis, we actually found that the majority of high achievers rated their trait mathematics anxiety significantly lower than their actual state mathematics anxiety. This means that high achievers underestimated their trait anxiety in comparison with their actual state anxiety levels.

Furthermore, in support of our assumption (Hypothesis 3), we found that the relationship between the trait-state discrepancy in mathematics anxiety and achievement group is mediated by academic self-concept. Higher levels of academic self-concept in mathematics corresponded with a smaller trait-state discrepancy in mathematics anxiety. Specifically, we found that high achievers with high mathematics self-concepts not only showed a smaller trait-state discrepancy in mathematics anxiety than low achievers, but also had negative trait-state discrepancy values. This finding demonstrates the influence that academic self-concept has on the trait-state discrepancy - it can even lead to an underestimation of trait anxiety in high achievers (i.e. negative values on the trait-state discrepancy). ${ }^{2}$

If state anxiety indeed reflects actual experiences of anxiety more validly than trait anxiety (Robinson \& Clore, 2002), our findings imply that even though high achievers appear well adapted to the classroom environment due to lower levels of trait and state anxiety than low achievers, they actually experience more anxiety in 
mathematics class than they are aware of (i.e. as reported in trait self-report measures). Therefore, when using trait anxiety measures as a proxy for student's actual anxiety, one has to always bear in mind the effects of other variables, such as academic achievement and academic self-concept, which can influence self-reported trait anxiety in either direction (i.e. overestimation or underestimation of trait anxiety).

The underestimation of trait anxiety could impact high achievers in multiple ways. On the one hand, it could be advantageous for high achievers to believe they experience less anxiety in mathematics class than they really felt because high levels of trait anxiety is negatively related to well-being, motivation, and learning behavior (Pekrun, Goetz, Titz, \& Perry, 2002). So this misperception of their actual anxiety (i.e. underestimation of trait anxiety in comparison with actual state anxiety levels) due to their high academic self-concepts could therefore result in conductive effects for high achiever's future academic choices, resiliency or general mental health (Taylor \& Brown, 1994; Wirtz, Kruger, Scollon, \& Diener, 2003).

On the other hand, underestimating how much anxiety they really experience in mathematics class could in the long run also have detrimental effects for high achievers. Specifically, this overconfidence (i.e. believing they are less anxious than they actually are) may lead high achievers to overestimate their abilities. Overestimating one's abilities is related to risky decision-making (Johnson \& Fowler, 2011), which could in turn negatively impact students' academic performance - specifically if the situation turns out to be highly threatening. This could result in high achievers being overwhelmed by their sudden feelings of anxiety and lacking the coping skills to deal with them. Therefore, it is important for teachers to remember that high achievers also experience anxiety while in class and they should address this anxiety by providing both low and high achievers with adequate coping skills.

Consistent with prior research (e.g. Goetz et al., 2013), our findings demonstrate that academic self-concept in the domain of mathematics, due to its high explanatory power $(65.3 \%)$, plays an important role in the discrepancy between trait and state mathematics anxiety. However, additional variables such as the perceived value of mathematics and interest in mathematics might also influence the trait-state discrepancy in mathematics anxiety, and should therefore also be investigated.

In his meta-analysis on math anxiety and performance, Hembree (1990) found that math anxiety peaks in grades 9 to 10 . Therefore, our sample only included 9th and 10th grade students in mathematics classes. Future research should extend our study and explore whether our findings generalize to different age groups. Furthermore, the exploration of a possible trait-state discrepancy in other subject domains than mathematics is indicated as well.

In summary, our results were in line with previous studies concerning the role of academic self-concept in explaining the trait-state discrepancy. We found that achievement group moderates the trait-state discrepancy in mathematics anxiety and that this relationship is mediated by academic self-concept. High achievers exhibited a smaller trait-state discrepancy than low achievers because of their higher academic self-concepts. However, unlike low achievers high achievers underestimated their trait anxiety and actually experienced more state anxiety than would have been expected based on their self-reported trait anxiety measures. Since state measures are believed to reflect actual anxiety, this study shows that math anxiety is a widespread emotion in classrooms - even among high achieving students - that deserves our attention. 


\section{Disclosure statement}

No potential conflict of interest was reported by the authors.

\section{Notes}

1. The correlation between achievement and academic self concept was quite high $(r=.82)$ which was mainly due to only comparing the two extreme groups (high vs. low achievers). As assumed, the Pearson correlation between achievement level and aca demic self concept in the whole sample (with the whole range of grades and levels of self concept) was lower $(r=.75, p<.01)$. The size of this correlation as related to the whole sample was in line with findings from numerous previous studies and meta analy ses (e.g. Goetz et al., 2013; Möller, Pohlmann, Köller, \& Marsh, 2009; Valentine, DuBois, \& Cooper, 2004).

2. Based on these findings, we were interested in the value of the mathematics self concept in which the intensity of trait and state anxiety was estimated equally or in other words at which point the values of the trait state discrepancy turned from positive (overestima tion of trait anxiety) to negative (underestimation of trait anxiety). We called this turning point the "flip threshold." To find this turning point, we conducted post hoc analyses which revealed that the majority of students in our sample with a mathematics self con cept of 3.81 (range 15 ) or higher showed negative values on the trait state discrepancy in anxiety, meaning higher values for state than for trait anxiety. Therefore, in our sam ple, we expected the so called "flip threshold" to be at a mathematics self concept level of 3.81. Results further revealed that only high achievers were in this group $(85 \%$ of the high achievers), which confirms past findings that a high academic self concept seems to be closely related to high academic achievement (Bailey, 1971). All the high achievers with a mathematics self concept of 3.81 or lower $(15 \%)$ had positive values on the trait state discrepancy, which indicates higher values for trait as compared to state anxiety.

\section{References}

Bailey, R. C. (1971). Self concept differences in low and high achieving students. Journal of Clinical Psychology, 27, 188 191. doi:10.1002/1097 679(197104)27:2<188:AID JCLP2270270208>3.0.CO;2 I

Bieg, M., Goetz, T., \& Lipnevich, A. A. (2014). What students think they feel differs from what they really feel Academic self concept moderates the discrepancy between stu dents' trait and state emotional self reports. PLoS ONE, 9, e92563. doi:10.1371/jour nal.pone.0092563

Buehler, R., \& McFarland, C. (2001). Intensity bias in affective forecasting: The role of tem poral focus. Personality and Social Psychology Bulletin, 27, 1480 1493. doi:10.1177/ 01461672012711009

Cohen, J. (1988). Statistical power analysis for the behavioural sciences (2nd ed.). Hillsdale, NJ: Erlbaum.

Federal Statistical Office [Statistisches Bundesamt]. (2015). Schnellmeldungsergebnisse zu Schülerinnen und Schülern der allgemeinbildenden und beruflichen Schulen Schuljahr 2014/15 [Preliminary results of general and vocational school students: 201415 academic year]. Retrieved from https://www.destatis.de/DE/Publikationen/Thematisch/Bil dungForschungKultur/Schulen/SchnellmeldungSchueler5211003158004.pdf

Goetz, T. (2004). Emotionales Erleben und selbstreguliertes Lernen bei Schülern im Fach Mathematik [Emotions and self regulated learning of students in mathematics]. Munich: Utz.

Goetz, T., Bieg, M., Lüdtke, O., Pekrun, R., \& Hall, N. C. (2013). Do girls really experience more anxiety in mathematics? Psychological Science, 24, 2079 2087. doi:10.1177/ 0956797613486989

Goetz, T., \& Hall, N. C. (2013). Emotion and achievement in the classroom. In J. Hattie \& E. M. Anderman (Eds.), International guide to student achievement (pp. 192 195). New York, NY: Routledge. 
Hembree, R. (1990). The nature, effects, and relief of mathematics anxiety. Journal for Research in Mathematics Education, 21, 33 46. doi:10.2307/749455

Johnson, D. D., \& Fowler, J. H. (2011). The evolution of overconfidence. Nature, 477, 317 320. doi:10.1038/nature10384

Kunter, M., Schümer, G., Artelt, C., Baumert, J., Klieme, E., \& Neubrand, M. (2002). PISA 2000: Dokumentation der Erhebungsinstrumente [PISA 2000: Documentation of scales]. Berlin: Heenemann GmbH \& Co.

Ma, X. (1999). A meta analysis of the relationship between anxiety toward mathematics and achievement in mathematics. Journal for Research in Mathematics Education, 30, 520 540. doi:10.2307/749772

Marsh, H. W. (1990). Self description questionnaire (SDQ) II: A theoretical and empirical basis for the measurement of multiple dimensions of adolescent self concept: An interim test manual and a research monograph. Macarthur: University of Western Sydney.

Marsh, H. W., \& Craven, R. (1997). Academic self concept: Beyond the dustbowl. In G. D. Phye (Ed.), Educational psychology series. Handbook of classroom assessment: Learn ing, achievement, and adjustment (pp. 131 198). San Diego, CA: Academic Press.

Möller, J., Pohlmann, B., Köller, O., \& Marsh, H. W. (2009). A meta analytic path analysis of the internal/external frame of reference model of academic achievement and academic self concept. Review of Educational Research, 79, 1129 1167. doi:10.3102/ 0034654309337522

Nagengast, B., \& Marsh, H. W. (2012). Big fish in little ponds aspire more: Mediation and cross cultural generalizability of school average ability effects on self concept and career aspirations in science. Journal of Educational Psychology, 104, 1033 1053. doi:10.1037/ a0027697

Pekrun, R. (2006). The control value theory of achievement emotions: Assumptions, corollar ies, and implications for educational research and practice. Educational Psychology Review, 18, 315 341. doi:10.1007/s10648 00690299

Pekrun, R., Goetz, T., \& Frenzel, A. C. (2006). Academic Emotions Questionnaire Mathe matics (AEQ M) User's manual. Munich: Department of Psychology, University of Munich

Pekrun, R., Goetz, T., Titz, W., \& Perry, R. P. (2002). Academic emotions in students' self regulated learning and achievement: A program of qualitative and quantitative research. Educational Psychologist, 37, 91 105. doi:10.1207/S15326985EP3702 4

Preacher, K. J., Rucker, D. D., \& Hayes, A. F. (2007). Addressing moderated mediation hypotheses: Theory, methods, and prescriptions. Multivariate Behavioral Research, 42, 185 227. doi:10.1080/00273170701341316

Raudenbush, S. W., \& Bryk, A. S. (2002). Hierarchical linear models: Applications and data analysis methods (2nd ed.). Thousand Oaks, CA: Sage.

Raudenbush, S., Bryk, A., Cheong, Y., Congdon, R., \& du Toit, M. (2011). HLM (Version 7.01) [Computer Software]. Lincolnwood, IL: Scientific Software International

Robinson, M. D., \& Clore, G. L. (2002). Belief and feeling: Evidence for an accessibility model of emotional self report. Psychological Bulletin, 128, 934 960. doi:10.1037/0033 2909.128.6.934

Spielberger, C., Gorsuch, R. L., \& Lushene, R. E. (1970). Manual for the state trait anxiety inventory. Palo Alto, CA: Consulting Psychologists Press.

Taylor, S. E., \& Brown, J. D. (1994). Positive illusions and well being revisited: Separating fact from fiction. Psychological Bulletin, 116, 21 27. doi:10.1037/0033 2909.116.1.21

Valentine, J. C., DuBois, D. L., \& Cooper, H. (2004). The relation between self beliefs and academic achievement: A meta analytic review. Educational Psychologist, 39, 111133. doi:10.1207/s15326985ep3902 3

Wilhelm, P., Perrez, M., \& Pawlik, K. (2011). Conducting research in daily life: A historical review. In M. Mehl \& R. Conner (Eds.), Handbook of research methods for studying daily life (pp. 62 186). New York, NY: Guilford.

Wirtz, D., Kruger, J., Scollon, C. N., \& Diener, E. (2003). What to do on spring break?: The role of predicted, on line, and remembered experience in future choice. Psychological Science, 14, 520 524. doi:10.1111/1467 9280.03455 